\section{Sat-nav savvy}

Colleagues

of the late

Steve Irwin (The

Crocodile Hunter) were stunned when one of

the saltwater crocs in their satellite-tracking study showed an amazing homing instinct - navigating more than 400 kilometres in less than 3 weeks to return to where it was captured.

\section{SCORECARD}

Ireland's smoking ban

It's not just Irish
people's lungs that
are benefiting - the
smoking ban is music to their ears, too. Instrument repairers have noticed a boost in the health of accordions, concertinas and bagpipes played in smoke-free pubs.

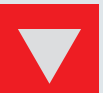

Greece's smoking trees Environmental group the WWF reports that vegetation will take 20 years to bounce back from the fires that raged across Greece during August, and that the fir forests will take more than a generation to recover.

\section{NUMBER CRUNCH}

\section{0 kilograms of illegal} black caviar were seized by Russian police in a raid last week.

$90 \%$ is the amount that beluga sturgeon stocks have declined in the past 20 years.

US\$7,500 is the price fetched by a kilogram of caviar in London, making it a tasty temptation for black-marketeers.

\section{ON THE RECORD}

\section{(c) think I could have} been an art dealer. I have pretty good taste. I've always liked portraits. For me, faces dominate my life. It's not about big boobs. It's about the face.

\section{Always."}

James Watson tells us what he might have done had he not turned his mind to unlocking the structure of DNA.

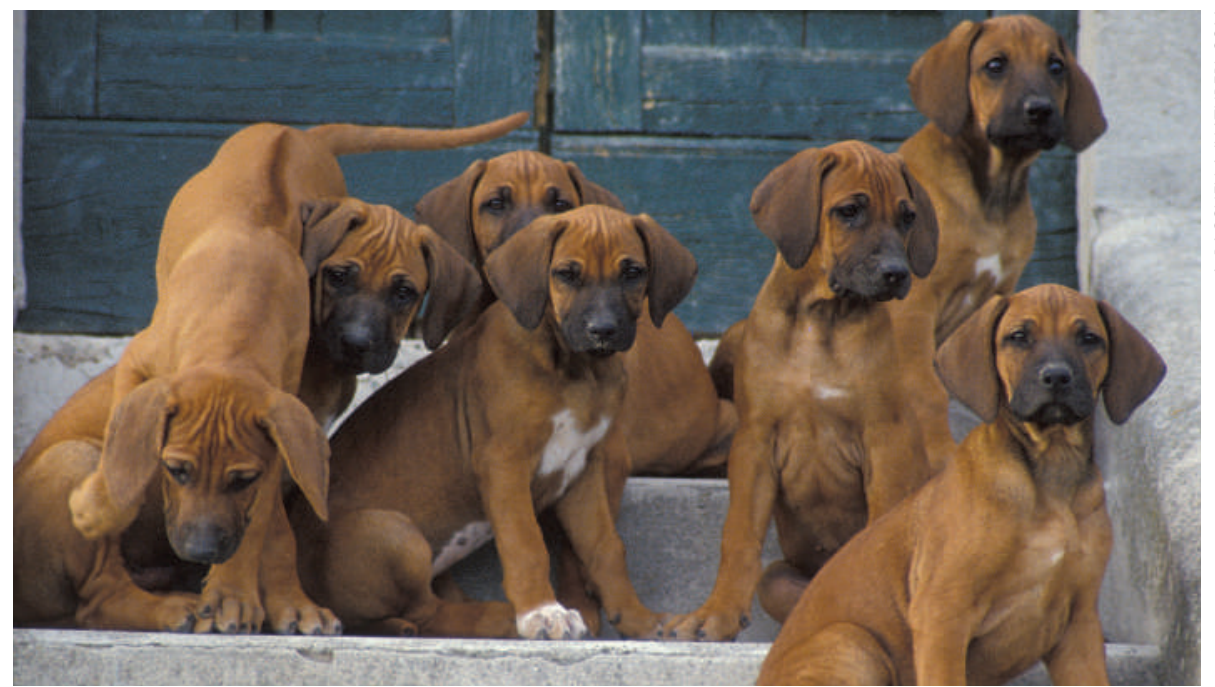

Geneticists used just 21 dogs to find the genes that code for the Rhodesian ridgeback's contrary hair.

\title{
Dogs help sniff out genes
}

Man's best friend is becoming the geneticist's too. Researchers have made good on the dog genome's promise: a quick-and-dirty way to find the genes responsible for physical traits using just a couple of dozen pooches and a gene chip.

Kerstin Lindblad-Toh, of the Broad Institute of Harvard and Massachusetts Institute of Technology in Cambridge, Massachusetts, and her colleagues have devised a method of locating the genes responsible for specific traits that requires as few as 10 animals with the feature and 10 without — as long as they are all the same breed ${ }^{1}$. The team has also identified the genes that give the Rhodesian ridgeback breed its ridge but additionally predispose the dogs to a crippling developmental disease called dermoid sinus ${ }^{2}$. Such feats were predicted when Lindblad-Toh's team mapped the dog genome $e^{3}$ but this is the first time they have been achieved.

The technique exploits the unique evolutionary history of dogs, which humans tamed from grey wolves between 15,000 and 100,000 years ago. Over centuries, humans have bred dogs, selecting for traits such as size and ability to herd sheep. Most of the 400 breeds descend from just a handful of hounds. The result: vast stretches of genetic similarity in dogs of the same breed, allowing geneticists to spot the few differences relatively easily. "Here you have the perfect genetic model," says Leif Andersson, a biologist at the Swedish University of Agricultural Sciences, in Uppsala, Sweden, who co-leads the project.
Using a gene chip that analysed about 27,000 single-letter differences across the entire dog genome, the team identified a region of 750,000 base pairs in the Rhodesian ridgeback genome that differed between ridged and unridged animals. The unridged version accounts for just $5 \%$ of ridgebacks because breeders select for the trait $^{1}$.

To identify the specific genes, the team turned to Thai ridgebacks, which exhibit the same feature without being closely related to the Rhodesians. By comparing the same DNA stretch between the breeds, the team discovered the culprit: extra copies of four genes involved in fetal development.

The finding helps explain the prevalence of dermoid sinus in the dogs. This painful development disorder, where the skin fails to separate from the nerve chord, affects nearly one-tenth of Rhodesian ridgebacks, says teammember Claire Wade, a geneticist at the Broad Institute. "Often the animals have to be put down," she says.

Dogs lacking the duplication of genes are unridged; those with one copy have a normal ridge; but having two copies also carries an $80 \%$ risk of dermoid sinus. The mechanism paves the way for geneticists to use the dog genome to help identify genes involved in disorders such as diabetes that also affect humans.

Ewen Callaway

Karlsson, E. et al. Nature Genet. doi:10.1038/ ng.2007.10 (30 September 2007).

2. Hillbertz, N. et al. Nature Genet. doi:10.1038/ ng.2007.4 (30 September 2007).

3. Lindblad-Toh, K. et al. Nature $438,803-819$ (2005). 